\title{
ONE APPROACH TO THE ANALYSIS OF IMPACT OF SHIFT-WORK INTRODUCTION ON UNIT COSTS IN SERIAL PRODUCTION
}

\author{
UDC: $658.524: 331.312 .64$ \\ Original Scientific Paper \\ Miroslav RADOJIČIĆ ${ }^{1}$, Jasmina VESIĆ VASOVIĆ ${ }^{2}$, Zoran NEŠIĆ \\ ${ }^{1}$ University of Kragujevac, Faculty of technical science, 32000 Čačak, 65 Svetog Save, Republic of Serbia \\ E-mail: miskoradojicic@gmail.com \\ ${ }^{2}$ University of Kragujevac, Faculty of technical science, 32000 Čačak, 65 Svetog Save, Republic of Serbia
}

Paper received: 15.04.2015.; Paper accepted: 20.05.2015.

\begin{abstract}
This paper is an approach to the impact of shift work on economic performance and size of the production series. The presented methodology has a significant impact on improving the quality of economic performance in terms of reducing the cost per unit of output in serial production. The paper is illustrated with a concrete example of the analysis and application of the methodology discussed with the software support.
\end{abstract}

Keywords: optimal batch size, shift-work, cost reduction, serial production.

\section{INTRODUCTION}

In production-oriented enterprises that have significantly higher production potential than those needed for the production of certain parts, production is organized in such a way that those parts are manufactured in series to meet the needs during the entire accounting period, or needs throughout the year. For the purpose of launching a certain number of pieces in production, which will be launched as a series, or launching of a certain size of series, certain costs appear that can be divided into two categories.

Many authors emphasize the importance of studying the problems of the size of production series. Theoretical and practical analyzes were conducted with different aspects:

- under a fixed-quantity and periodic delivery policy (Sarker and Parija, 1994)

- in a just-in-time delivery system (Golhar and Sarker, 1992; Jamal and Sarker, 1993)

- with a fixed-interval in a delivery schedule (Hill, 1996; Sarker and Parija, 1996)

Contemporary directions of research advance this issue with many aspects:

- Optimal bach size snd impact to warehousing (Bertazzi, 2009),
- Purchasing and supply chain management analysis (Weele, 2009)

- Impact of information control problems (Zaremba, 2014)

- The impact of automation on scale and scope of production (Alcorta, 2003)

- Batch costing (Mathur, 2011)

- Implementation of Optimization Models and Quantitative Methods (Christou, 2011)

It is undisputed that in a "well-managed process, the batch size will balance transaction and holding costs" (HBR's, 2014). In order to increase the economic efficiency of production and business of enterprises, we will determine the size of a series by which minimum value of production costs reduced to unit product will be realized; in metal production it is usually a piece ( $\mathrm{din} / \mathrm{pcs})$. It should be noted that the value of funds spent for the production in the cycle of operations is transferred to the value of the new product. The company is trying to shorten the production cycle. The duration of the production cycle represents a criterion for the validity of the production process. If it is a longer production cycle, the engagement of working capital is higher, and the increase of cost of higher. 


\section{CHARACTERISTICS OF SHIFT-WORK IN THE PRODUCTION}

Standard daily hours imply the traditional working time that takes place in the first part of the day (that is the visible part of the day). Shifts in the production represent the effective operation of the workers in time whose beginning and end progress from day to day, with workers working in the first, second or third shift, or from week to week, and so on. Organization of shift work in manufacturing, in continuous or discontinuous technological processes, means that workers rotate at machines or other workplaces, the same or similar jobs, while the technological process lasts longer than work time per shift. Shifts can be organized in such a way that they do not include night work, e.g. work in two shifts. It is very often used in practice, if it is not a continuous process. The need for the shift work, both in manufacturing and in service providing area, is increasing round the world. Regardless of the fact that this kind of work causes significant additional mental and physical efforts for employees, it may have negative effects on the quality of their jobs and lead to errors. One should strive to better organization of working time in work shifts in order to have the negative effects reduced to a minimum.

According to the Labour Law, the right of an employee to increased earnings at the amount determined by the general act and the employment contract is established for night work and shift work. Regarding the organization of the shift and night work, it should be noted that this is an autonomous right of the employer, who decides whether the work in the company will be organized in one, two or three shifts. For an employee, shift work may be evaluated when determining the basic earnings, as one of the elements that makes up the basic earnings or through increased earnings, the corresponding percentage amount (e.g., at least $26 \%$ ), if it is not evaluated through basic earnings. In further considerations, in order to simplify the model for calculation of optimal batch size, it will be considered that the shift work of employees in the manufacturing has already been valued through the coefficient of work, through the system of paying an employee.

\section{OPTIMIZATION OF COSTS AND BACH SIZE}

The optimal batch size, i.e. optimization of the number of pieces launched in a series, which is calculated and explained here, refers to the parts and not the assemblies or to the product as a whole. The approach considered here is based only on economic criteria, i.e. the requirement that cost function of a particular series, reduced to a unit of the product, is minimized. In this regard, valuation code obtained for the conditions of work in one, two and the three shifts will be discussed and compared. We will consider the cost structure of production of a series. It can be immediately emphasized that some of the costs act independently of the colour of parts, pieces of the series and these are permanent (fixed) costs $(S)$ and consist of costs of series forming, technical and operational preparations. These costs may be very large in some types of production but also very small in some cases in the metal processing industry. This type of costs $(S)$, depending on the number of pieces in the series $(q)$, changes according to the law of hyperbole, but this type of cost per one piece is smaller if the number of pieces in the series is higher, and vice versa $s=S / q$ [din/pcs].

On the other hand, with the increase of the number of pieces in the series (q), interest costs on working capital grow, because in this way the material remains in the production longer if the number of pieces in the series is bigger, if the production time standard is higher etc. (Božin and Radojičić, 1997).

All costs (as a function of the number of pieces in the series) reduced to one piece are equal to the sum:

$$
t_{s r}=\mathrm{s}+\mathrm{t}_{\mathrm{pr}}=\frac{\mathrm{S}}{\mathrm{q}}+\mathrm{aq}
$$

where the optimal series or optimal number of pieces can be determined by the following formula:

$$
q_{\text {opt }}=\sqrt{\frac{S}{a}}
$$

where "a" is:

$$
a=\frac{t_{m d} \cdot t_{n} \cdot p}{60 \cdot 250 \cdot r \cdot 100}
$$

$t_{m d}$ - value of direct materials for one piece

$t_{n}$ - norm of time per piece

$p$-interest rate

In metal-processing companies it is necessary to calculate optimal batch size based on economic criteria with minimal production costs reduced to the product, piece. For the input data: total fixed costs: $S=63000$ [din/ser]; the cost of materials per 
piece: $t_{m d}=800 \quad[\mathrm{din} / \mathrm{pcs}] ;$ standard time of production per piece: $t_{n}=5 \mathrm{~min} / \mathrm{pcs}$ and interest rate: $p=14 \%$

The optimal series, which is launched in the production with the request for minimum production costs per piece, can be calculated with formula (2). If the work is done in one shift:

$$
\begin{aligned}
& a_{1}=\frac{800 \cdot 5 \cdot 14}{60 \cdot 250 \cdot 7 \cdot 100}=0.005333 \\
& q_{\text {opt }_{1}}=\sqrt{\frac{S}{a_{1}}}=\sqrt{\frac{63000}{0.005333}} \approx 3438[\mathrm{pcs} / \mathrm{ser}]
\end{aligned}
$$

$$
q_{\text {opt }_{2}}=\sqrt{\frac{S}{a_{2}}}=\sqrt{\frac{63000}{0.00266}} \approx 4858[\mathrm{pcs} / \mathrm{ser}]
$$

For the work in three shifts:

$$
q_{\text {opt }_{3}}=\sqrt{\frac{S}{a_{3}}}=\sqrt{\frac{63000}{0.00177}} \approx 5954[\mathrm{pcs} / \mathrm{ser}]
$$

The flow of the calculation for all volume of production is shown in Figure 1.

The optimum number of pieces is the largest if the

\begin{tabular}{|c|c|c|c|c|c|c|c|}
\hline$q$ & $s$ & tpr1 & tsr1 & tpr2 & tsr2 & tpr3 & tsr3 \\
\hline 500 & 126,000 & 2,667 & 128,667 & 1,333 & 127,333 & 0,889 & 126,889 \\
\hline 1000 & 63,000 & 5,333 & 68,333 & 2,667 & 65,667 & 1,778 & 64,778 \\
\hline 1500 & 42,000 & 8,000 & 50,000 & 4,000 & 46,000 & 2,667 & 44,667 \\
\hline 2000 & 31,500 & 10,667 & 42,167 & 5,333 & 36,833 & 3,556 & 35,056 \\
\hline 2500 & 25,200 & 13,333 & 38,533 & 6,667 & 31,867 & 4,444 & 29,644 \\
\hline 3000 & 21,000 & 16,000 & 37,000 & 8,000 & 29,000 & 5,333 & 26,333 \\
\hline 3500 & 18,000 & 18,667 & 36,667 & 9,333 & 27,333 & 6,222 & 24,222 \\
\hline 4000 & 15,750 & 21,333 & 37,083 & 10,667 & 26,417 & 7,111 & 22,861 \\
\hline 4500 & 14,000 & 24,000 & 38,000 & 12,000 & 26,000 & 8,000 & 22,000 \\
\hline 5000 & 12,600 & 26,667 & 39,267 & 13,333 & 25,933 & 8,889 & 21,489 \\
\hline 5500 & 11,455 & 29,333 & 40,788 & 14,667 & 26,121 & 9,778 & 21,232 \\
\hline \multirow[t]{2}{*}{6000} & 10,500 & 32,000 & 42,500 & 16,000 & 26,500 & 10,667 & 21,167 \\
\hline & \$A\$17/A2 & \$E $\$ 17^{*} A 2$ & $(\$ A \$ 17 / A 2)+C 2$ & \$E $\$ 20^{*} \mathrm{~A} 2$ & $(\$ A \$ 17 / A 2)+E 2$ & \$E $\$ 22^{*} \mathrm{~A} 2$ & $(\$ A \$ 17 / A 2)+G 2$ \\
\hline Total fixed cost: & $\mathrm{Tm}$ & tn & $\mathrm{p}$ & a1 & & & \\
\hline \multirow[t]{6}{*}{63000} & 800 & 5 & 14 & 0,0053333 & & & \\
\hline & & & & $\left(\$ B \$ 17^{\star} \$ C \$ 17^{*}\right.$ & $\left.{ }^{*} \$ D \$ 17\right) /\left(250^{*} 7^{*} 6\right.$ & $60 * 100)$ & \\
\hline & & & & a2 & & & \\
\hline & & & & 0,0026667 & & & \\
\hline & & & & a3 & & & \\
\hline & & & & 0,0017778 & & & \\
\hline
\end{tabular}
company works in three shifts (Figure 2) $q_{\text {opt } 3}>q_{\text {opt } 2}>q_{\text {opt } 1}$.

For the work in two shifts:

Figure 1: Calculation for all volumes of production

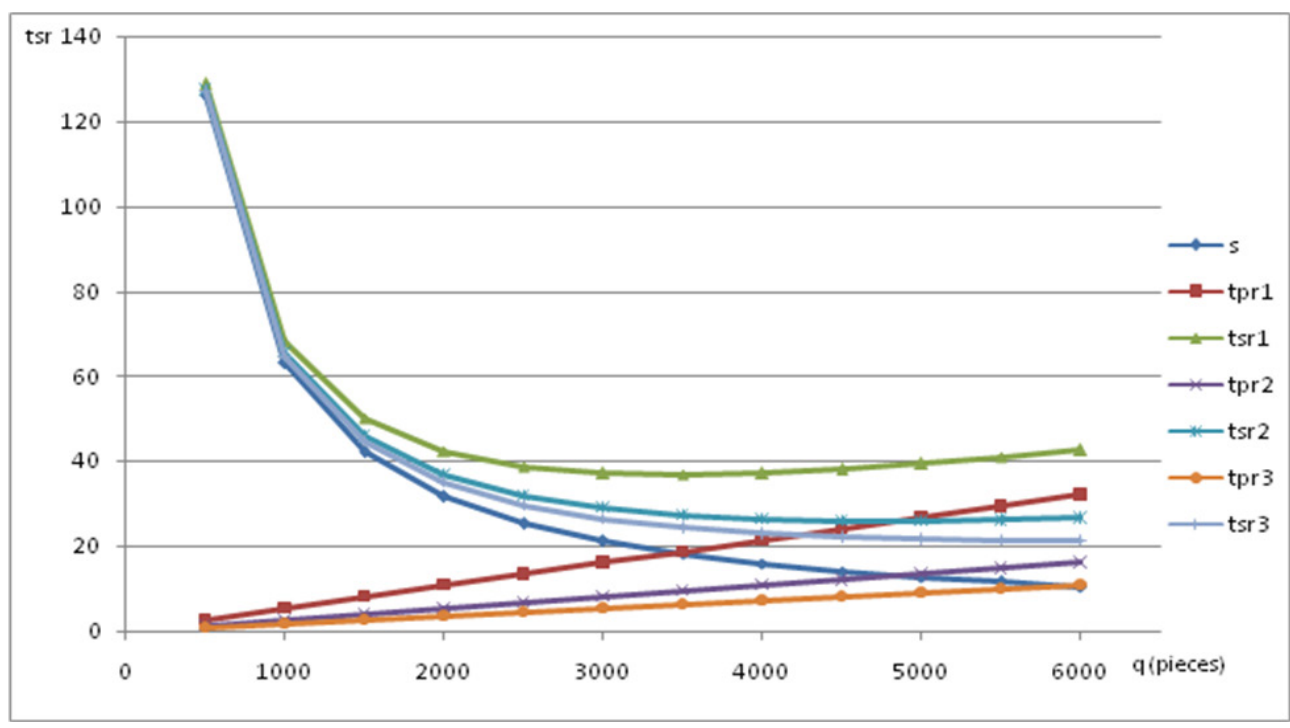

Figure 2: Comparison of costs for different volumes of production

By introducing the second shift, there is a significant decrease in unit costs and the need to launch a larger number of pieces in a series. By organizing the work in three shifts, the lowest costs and the largest series are obtained. This indicates 
that the work in triple shifts has even greater cost savings compared to double shift work.

If we introduce shift work it makes possible:

- lowering of the cost

- better utilization of production capacity of enterprises

- increase of the ratio of total working capital turnover as a measure of performance indicators and management of the working capital

- shortening of the production cycle and so on.

\section{CONCLUSION}

This paper presents and analyzes the characteristics of shift work in terms of economic efficiency of production. Optimization model presented in this paper is based on the exact parameters and calculates the cost in a function of the number of pieces in the batch. The analysis includes the costs of production, reduced per unit of production. Economic analysis clearly indicates that the work in three shifts affects the increasing of the optimal production volume. Taking into account the human factor, it is more humane to organize the work in two shifts, although the best economic effects are achieved by work in three shifts. The presented methodology has a significant impact on improvement of the quality of economic performance in terms of reducing the cost per unit of output in serial production.

This paper demonstrates the importance and relevance of economic batch size in industrial production in terms of reducing product costs. The developed optimization model can be widely used in the planning and preparation of production in industrial enterprises.

\section{REFERENCES}

. HBR's 10 Must Reads Series. (2014). Harvard Business Review from https://hbr.org/store/landing/mustreads
Alcorta, L. (2003). Flexible Automation in Developing Countries: The Impact on Scale and Scope and the Implications for Location of Production: UK: Routledge.

Bertazzi, L., Speranza, M. G., \& Nunen, J. (2009). Innovations in Distribution Logistics. Berin: Springer.

Božin, M., \& Radojičić, M. (1997). Organization and management [in Serbian]. Čačak, Serbia: University of Kragujevac, Technical faculty in Čačak.

Christou, I. T. (2011). Quantitative Methods in Supply Chain Management: Models and Algorithms, . London-New York: Springer Science \& Business Media.

Golhar, D. Y., \& Sarker, B. R. (1992). Economic manufacturing quantity in a just-in-time delivery system. International Journal of Production Research, 30(5), 961-972.

Hill, R. M. (1996). Optimizing a production system with a fixed delivery schedule. Journal of the Operational Research Society, 47, 956-960.

Jamal, A. M. M., \& Sarker, B. R. (1993). An optimal batch size for a production system operating under a just-in-time delivery system. International Journal of Production Economics, 32(2), 255-260.

Mathur. (2011). Accounting For Management. New Delhi: Tata McGraw-Hill Education.

Sarker, B. R., \& Parija, G. R. (1994). An optimal batch size for a production system operating under a fixedquantity, periodic delivery policy. Journal of the Operational Research Society, 45(8), 591-600.

Sarker, B. R., \& Parija, G. R. (1996). Optimal batch size and raw material ordering policy for a production system with a fixed-interval, lumpy demand delivery system. European Journal of Operational Research, 89(3), 593-608.

van Weele, A. J. (2009). Purchasing and Supply Chain Management: Analysis, Strategy, Planning and Practice. Andover: Cengage Learning EMEA.

Zaremba, M. B. (2014). Information Control Problems in Manufacturing Technology 1992: Selected Papers from the 7th IFAC/IFIP/IFORS/IMACS/ISPE Symposium, Toronto, Ontario, Canada, 25 - 28 May 1992: Elsevier.

\section{ACKNOWLEDGMENT}

The research presented in this paper was supported by the Ministry of Education, Science and Technological Development of the Republic of Serbia under Grant TR35017. 